\title{
A mask to modify inspired air temperature and humidity and its effect on exercise induced asthma
}

\author{
M Nisar, D P S Spence, D West, J Haycock, Y Jones, M J Walshaw, J E Earis, \\ P M A Calverley, M G Pearson
}

\begin{abstract}
Background Heat and moisture loss from the respiratory tract during exercise are important triggers of exercise induced asthma.

Methods A new heat and moisture exchange mask has been developed which both recovers exhaled heat and water and has a sufficiently low resistance for use during exercise. The effect of the mask on inspired air temperature was studied in four normal subjects. Eight asthmatic subjects performed identical exercise protocols on three separate days, breathing room air through a conventional mouthpiece, a dummy mask, and the new heat and moisture exchange mask. Seven different asthmatic subjects exercised while breathing cold air at $-13^{\circ} \mathrm{C}$ through a dummy or active mask. Results All subjects found the new mask comfortable to wear. The mean inspired temperature when the mask was used rose to $32.5(1.4)^{\circ} \mathrm{C}$ when normal subjects breathed room air at $24^{\circ} \mathrm{C}$ and to $19 \cdot 1(2 \cdot 7)^{\circ} \mathrm{C}$ when they inhaled subfreezing air at $-13^{\circ} \mathrm{C}$. The heat and moisture exchange mask significantly reduced the median fall in forced expiratory volume in one second $\left(F E V_{1}\right)$ after exercise to $13 \%$ (range 049\%) when asthmatic subjects breathed room air compared with $33 \%(10-65 \%)$ with the dummy mask and $28 \%(21-70 \%)$ with the mouthpiece. The fall in $F_{1}$ when the asthmatic subjects breathed cold air was $10 \%(0-26 \%)$ with the heat and moisture exchange mask compared with $22 \%(13-51 \%)$ with the dummy mask.
\end{abstract}

Conclusion Use of a heat and moisture exchange mask can raise the inspired temperature and humidity and ameliorate the severity of exercise induced asthma. The mask may be of practical value in non-contact sport or for people working in subzero temperatures.

\section{Introduction}

Bronchoconstriction can be induced by exercise in about three quarters of all asthmatic subjects. ${ }^{1}$ The trigger is thought to be respiratory heat loss, ${ }^{2}$ respiratory moisture loss, ${ }^{3}$ or a combination of the two, with a further effect from the exercise itself. ${ }^{4}$ The severity of exercise induced asthma can be reduced by increasing the temperature and humidity of inspired air. ${ }^{56}$

In one study surgeons' paper theatre masks produced a slight amelioration of exercise induced bronchoconstriction, presumably by the rebreathing of warm humid air. ${ }^{7}$ Attempts to produce effective air conditioning of inspired air have resulted in several small devices which are used in anaesthetic practice. These heat-moisture exchangers function reasonably well at the low flow rates (less than $1 \mathrm{l} / \mathrm{s}$ ) found within anaesthetic circuits. However, at flow rates of $0.5 \mathrm{l} / \mathrm{s}$ a driving pressure of up to $7.5 \mathrm{~cm} \mathrm{H}_{2} \mathrm{O}$ is required, which increases further as the device becomes saturated with water vapour. ${ }^{8}$ Thus for most asthmatic patients the only practical means of controlling their exercise induced asthma is drug treatment.

A new heat exchange element has been devised that combines fast heat-moisture transfer with low resistance even at high flows. We describe the characteristics of this mask and assess whether it warms inspired air and has an effect on the severity of exercise induced asthma.

\section{Subjects, materials and methods}

THE MASK

The heat exchanger element is a new design (patents pending) (fig 1). It consists of an aluminium 3-6 $\mathrm{mm}$ honeycomb matrix supported between two $0.1 \mathrm{~mm}$ layers of polypropylene mesh. The honeycomb has a low mass but high surface area. The polypropylene mesh ensures that there is turbulent airflow through the matrix and thus good airmatrix contact. The whole element has an area of $25 \mathrm{~cm}^{2}$ and a depth of $2 \mathrm{~cm}$. Resistance to air flow at low flow rates is negligible and reaches $0.17 \mathrm{~cm} \mathrm{H} \mathrm{H}_{2} \mathrm{O} / \mathrm{l} / \mathrm{s}$ at a flow rate of $6 \mathrm{l} / \mathrm{s}$. This element has been incorporated into a face mask with a total dead space (mask and element) of $160 \mathrm{ml}$ (fig 1). The mask is lightweight (75 g) and washable, and can be sterilised. The new aspect of the design is the low mass to surface area and large pore size. It does not saturate even with prolonged use because of the loose nature of the honeycomb matrix.

\section{MEASUREMENTS}

Temperatures were recorded with fast response type $K$ thermocouples, the outputs of which were amplified, calibrated, and recorded on a chart recorder. End tidal carbon dioxide concentrations were measured on an Engstrom 


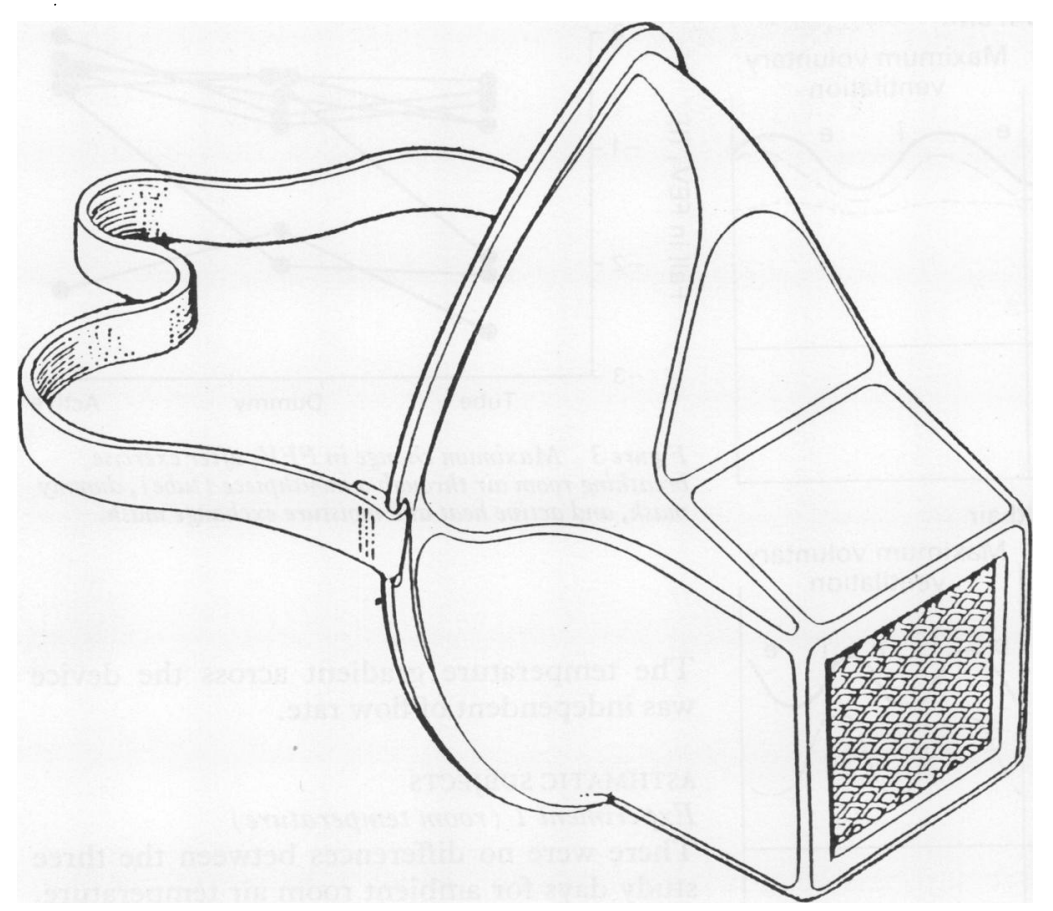

Figure 1 Heat and moisture exchange mask.

infrared capnograph and arterial oxygen saturations with a Biox 3700 pulse oximeter. All spirometric measurements were made on the same dry spirometer (Vitalograph).

Air temperature was measured immediately proximal and distal to the element, with care being taken to ensure that the thermocouples were sited in the centre of the airstream and were not in contact with either the element or the subject. The temperature difference across the element within each breath was recorded on a chart recorder. The average temperature (end expiratory temperature-end inspiratory temperature) was calculated for each of 10 to 15 successive breaths and a mean of these values obtained for each test. This was done in the second and last minute of each exercise test. The mean inspired temperature in the tables refers to the patient group mean of individual mean temperatures for a given test protocol.

STUDIES IN NORMAL SUBJECTS

To assess the effect of breathing pattern on the efficacy of the mask, four normal subjects breathed through the mask with two different breathing patterns: tidal breathing for five minutes followed by 15 seconds of maximum voluntary ventilation. These manoeuvres were done first with room air at $24^{\circ} \mathrm{C}$ and then with the mask connected to a supply of cold air from a cold air generator at $-13^{\circ} \mathrm{C}$.

\section{STUDIES IN PATIENTS WITH EXERCISE INDUCED} ASTHMA

Experiment 1

Eight patients with a clinical history of bronchoconstriction after exercise (four males, mean age 27 years (range 13-42)) were studied. Mean baseline forced expiratory volume in one second $\left(\mathrm{FEV}_{1}\right)$ was $2 \cdot 71(99 \%$ of predicted values). All patients used $\beta$ agonist inhalers regularly, but six were also taking an inhaled steroid and three an oral theophylline preparation.

Each subject attended at the same time on three consecutive days, having omitted taking inhaled $\beta$ agonists for at least six hours and oral theophyllines for 24 hours. They rested for 30 minutes, after which the best $\mathrm{FEV}_{1}$ and forced vital capacity (FVC) of three acceptable attempts was recorded (baseline values). Exercise was performed on an electronically braked cycle ergometer. The duration (6 to 9 minutes) and workload ( 50 or $75 \mathrm{~W}$ ) were set according to height and were the same for each of the three study days in each subject. FEV and FVC were measured again at the end of exercise and at three minute intervals until baseline $\mathrm{FEV}_{1}$ had been regained.

On the first visit the subjects breathed through a cardboard tube mouthpiece $(22 \mathrm{~mm}$ diameter) with thermocouples at each end and a carbon dioxide sampling probe in the middle. The mean inspired temperature was determined for each test (see above). Pulse rate was recorded before and during exercise. For the next two days the same protocol was followed except that the tube was replaced by a control mask (a black rubber anaesthetic mask of similar dead space) or the active mask in random order. Care was taken to ensure correct positioning of the thermocouples. After exercise was completed subjects continued to wear the masks except when spirometric measurements were being recorded.

\section{Experiment 2}

A further seven subjects (three male) with a mean age of 23 (range 19-30) years took part. They had a mean $\mathrm{FEV}_{1}$ of $3.71(98 \%$ of predicted values) and a history of exercise induced asthma. All used an inhaled $\beta$ agonist and two were taking an inhaled steroid. All abstained from inhaling a $\beta$ agonist for at least six hours before each study. Inhaled steroids continued to be taken.

Subjects attended on two consecutive days at the same time of day. They exercised for six minutes on the same cycle ergometer and breathed through the active heat and moisture exchange mask or a dummy mask of similar appearance in random order. Subjects were unaware which was the active mask but were aware of the aims of the experiment. The masks were connected to a supply of cold air $\left(-13^{\circ} \mathrm{C}\right)$ from a cold air generator and the workload adjusted during the first two minutes of day 1 to achieve a workload of $75 \%$ of the predicted maximum for that subject. Again thermocouples were positioned immediately proximal and distal to the mask. Spirometry was performed before, immediately after, and at three minute intervals until the pre-exercise $\mathrm{FEV}_{1}$ was regained or up to 30 minutes after exercise, whichever was the sooner.

\section{ANALYSIS}

Statistical comparisons were performed with non-parametric Wilcoxon signed rank tests or by Student's paired test as appropriate. 
Figure 2 Effect of active (spirometer tube (-- - - ) on inspired temperature with different breathing patterns and ambient air temperature. Room air $=24^{\circ} \mathrm{C}$, cold air $=-13^{\circ} \mathrm{C}$. e-expiration, i-inspiration.
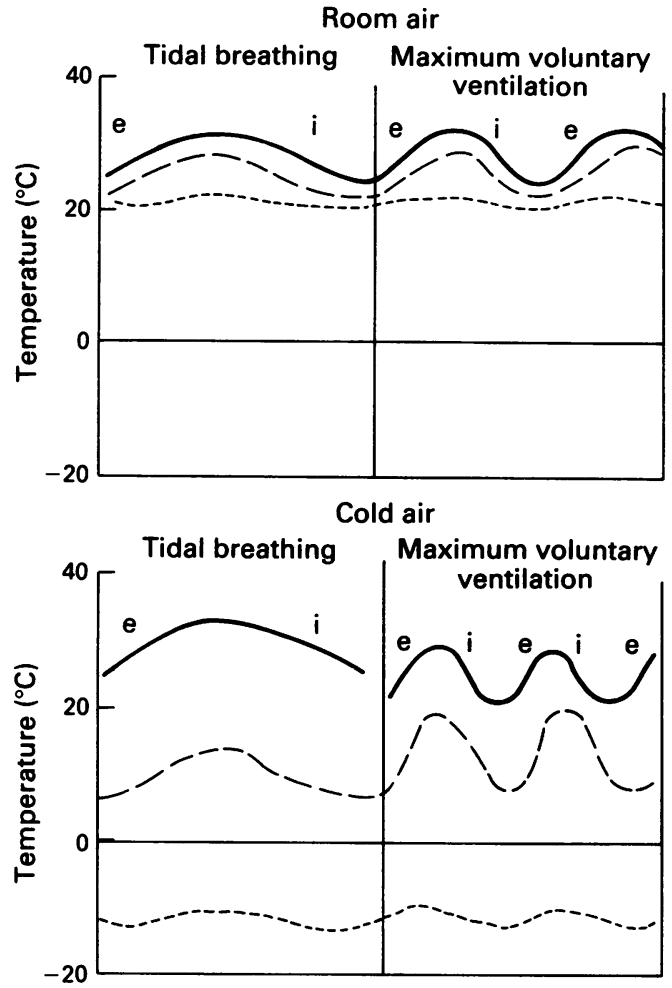

\section{Results}

NORMAL SUBJECTS

When normal subjects breathed room air quietly at $24^{\circ} \mathrm{C}$ the mean (SD) inspired temperature immediately proximal to the mouth was $32.5(1.4)^{\circ} \mathrm{C}$ with the heat and moisture exchange mask and $26.2(0.5)^{\circ} \mathrm{C}$ with the dummy mask (fig 2). The increased flow rate across the device during maximum voluntary ventilation did not affect these inspired temperatures significantly. The difference between active and dummy masks was increased when the ambient air temperature was low $\left(-13^{\circ} \mathrm{C}\right)$ : the mean inspiratory temperature was $22.9(1.1)^{\circ} \mathrm{C}$ with the active mask and $8.5(2.5)^{\circ} \mathrm{C}$ with the dummy mask.

Table 1 Mean (SD) values for room temperature, baseline lung function and end tidal carbon dioxide concentration, and pulse rates during the last minute of exercise in eight asthmatic subjects during experiment 1

\begin{tabular}{|c|c|c|c|}
\hline & $\begin{array}{l}\text { Spirometer } \\
\text { tube }\end{array}$ & $\begin{array}{l}\text { Control } \\
\text { mask }\end{array}$ & $\begin{array}{l}\text { Active } \\
\text { mask }\end{array}$ \\
\hline $\begin{array}{l}\text { Room temperature }\left({ }^{\circ} \mathrm{C}\right) \\
\text { FEV }_{1}(1) \\
\text { FVC (I) } \\
\text { End tidal carbon dioxide }(\%) \\
\text { Pulse rate }\end{array}$ & $\begin{array}{l}25(2) \\
2.7(0 \cdot 7) \\
3.7(1 \cdot 0) \\
5 \cdot 1(0 \cdot 5) \\
136(7)\end{array}$ & $\begin{array}{l}25(3) \\
2.8(0.5) \\
3.8(1.2) \\
5.0(0.6) \\
134(5)\end{array}$ & $\begin{array}{l}25(2) \\
2 \cdot 7(1 \cdot 0) \\
3 \cdot 8(1 \cdot 3) \\
5 \cdot 1(0 \cdot 5) \\
135(5)\end{array}$ \\
\hline
\end{tabular}

$\mathrm{FEV}_{1}=$ forced expiratory volume in one second; FVC $=$ forced vital capacity

Table 2 Mean (SD) temperature gradients across the devices and maximum changes in pulmonary function after exercise for the three study days

\begin{tabular}{|c|c|c|c|}
\hline & $\begin{array}{l}\text { Cardboard } \\
\text { tube }\end{array}$ & $\begin{array}{l}\text { Control } \\
\text { mask }\end{array}$ & $\begin{array}{l}\text { Active } \\
\text { mask }\end{array}$ \\
\hline $\begin{array}{l}\text { Mean (SD) temperature gradient }\left({ }^{\circ} \mathrm{C}\right) \\
\text { FEV.: }\end{array}$ & $0.7(0.6)$ & $2.4(1.9)$ & $6.3(1.0)^{\star}$ \\
\hline $\begin{array}{l}\text { Median fall (1) } \\
\text { Range (1) } \\
\text { Median fall (\%) } \\
\text { Range (\%) } \\
\text { Mean (SD) time to nadir (min) }\end{array}$ & $\begin{array}{l}0 \cdot 8 \\
0 \cdot 4-2 \cdot 6 \\
28 \\
21-70 \\
12 \cdot 4(2 \cdot 1)\end{array}$ & $\begin{array}{l}0.6 \\
0.4-2 \cdot 0 \\
33 \\
10-65 \\
9 \cdot 8(2 \cdot 4)\end{array}$ & $\begin{array}{l}0.3^{\star} \\
0-2 \cdot 2 \\
13^{\star} \\
0-49 \\
10 \cdot 5(1 \cdot 9)\end{array}$ \\
\hline
\end{tabular}

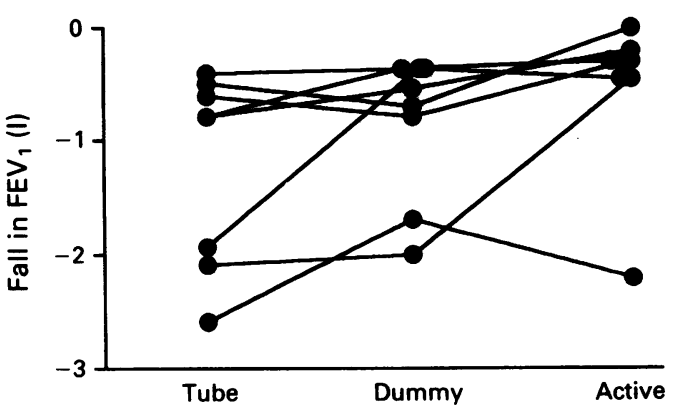

Figure 3 Maximum change in $F E V$, after exercise breathing room air through a mouthpiece (tube), dummy mask, and active heat and moisture exchange mask.

The temperature gradient across the device was independent of flow rate.

\section{ASTHMATIC SUBJECTS}

Experiment 1 (room temperature)

There were no differences between the three study days for ambient room air temperature, baseline lung function, carbon dioxide tension during exercise, or workrate achieved (as assessed by pulse rate) during the exercise tests (table 1).

The mean inspired air temperature gradient across the mask was $2 \cdot 4^{\circ} \mathrm{C}$ (range $0-5$ ) with the dummy mask and $6.3^{\circ} \mathrm{C}$ (range 5-7.9) with the heat and moisure exchange device (see table 2). The mean inspired temperature remained constant for each subject during the six minutes of cycle exercise.

All eight subjects developed exercise induced bronchoconstriction on the first study day with a median (range) fall in $\mathrm{FEV}_{1}$ of 0.8 $(0.4-2 \cdot 6) 1$ (table 2). The median fall in FEV was $0.6(0.4-2.0) 1$ with the control mask and $0.3(0-2.2) 1$ with the active heat exchange mask $(\mathrm{p}<0.02)$. The timing of the $\mathrm{FEV}_{1}$ nadir after exercise was unaffected by the masks. All subjects reported that the new heat and moisture exchange mask was comfortable to wear during exercise. Figure 3 shows the maximum change in $\mathrm{FEV}_{1}$ with the mouthpiece and the two masks.

\section{Experiment 2 (cold air)}

The mean temperature of the inspired air rose from $-13^{\circ} \mathrm{C}$ to $10(5)^{\circ} \mathrm{C}$ with the control mask and to $19(7)^{\circ} \mathrm{C}$ with the active mask (table 3 ).

There were no significant differences in preexercise spirometric results and maximum pulse rates on the two test days. Mean arterial oxygen saturation was similar on the two days, but end tidal carbon dioxide tension during exercise was slightly, though significantly, lower on the day when the control mask was used $(3.73(0.11) \mathrm{kPa})$ than on the day when the active mask was used $(3.97(0.11) \mathrm{kPa}$; $\mathrm{p}<0.02)$.

All subjects developed exercise induced bronchoconstriction when wearing the dummy mask, the median (range) fall in $\mathrm{FEV}_{1}$ being 0.8 $(0.5-1.5)$ 1. The median fall in $\mathrm{FEV}_{1}$ was significantly less with the active mask (0.3 $(0-0.75) 1 ; p<0.02)$ (fig 4). 
Table 3 Results of exercise breathing cold air in seven subjects in experiment 2

\begin{tabular}{|c|c|c|}
\hline & $\begin{array}{l}\text { Control } \\
\text { mask }\end{array}$ & $\begin{array}{l}\text { Active } \\
\text { mask }\end{array}$ \\
\hline $\begin{array}{l}\text { Mean (SD) air temperature } \\
\left({ }^{\circ} \mathrm{C}\right)\end{array}$ & $-11 \cdot 5(2 \cdot 7)$ & $-12 \cdot 2(1 \cdot 7)$ \\
\hline $\begin{array}{l}\text { Mean (SD) inspired air } \\
\text { temperature }\end{array}$ & $10 \cdot 4(5 \cdot 3)$ & $19 \cdot 1(7 \cdot 2)^{\star}$ \\
\hline $\begin{array}{l}\text { Median maximum fall (l) } \\
\text { Range (1) } \\
\text { Median maximum fall (\%) } \\
\text { Range (\%) }\end{array}$ & $\begin{array}{l}0 \cdot 8 \\
0 \cdot 5-1 \cdot 5 \\
22 \\
13-51\end{array}$ & $\begin{array}{l}0.3 \\
0-0.75^{\star} \\
10 \\
0-26^{\star}\end{array}$ \\
\hline $\begin{array}{l}\text { Pulse rate: } \\
\text { Mean (SD) maximum } \\
\text { End tidal carbon dioxide: }\end{array}$ & $155(9)$ & $154(4)$ \\
\hline Mean (SD) (kPa) & $3.73(0.28)$ & . $3.97(0.29)^{\star \star}$ \\
\hline
\end{tabular}

TIME COURSE OF BRONCHOCONSTRICTION

The time course of bronchoconstriction varied between patients but was similar in all but one subject with the active and control masks. One patient had an earlier and smaller fall in $\mathrm{FEV}_{1}$ after exercise while wearing the active mask $(6 v$ 12 minutes) that returned to baseline values faster ( $9 v 23$ minutes) than when the control mask was worn. Immediate bronchodilatation after exercise was not seen in any subject wearing the control mask but was seen in four subjects when wearing the active mask. Recovery from exercise induced bronchoconstriction was faster with the active mask (median time to recovery 12 minutes) than with the control mask. $\mathrm{FEV}_{1}$ returned to baseline values in all subjects by 30 minutes with the active mask compared with only three with the control mask. All patients reported that the mask was comfortable to wear.

\section{Discussion}

This is not the first attempt to produce a heatexchange mask for use in exercise. The new mask differs from previous models in two important respects. Firstly, the materials used for the heat and moisture exchanger have a very high surface area to mass ratio, which when associated with turbulent flow results in very rapid heat and moisture transfer. Thus similar temperature gradients are seen at low and high flow rates, and even under severe conditions; with very cold external air the warming effects are pronounced and independent of flow rates (fig 2). Secondly, the heat and moisture exchange element has a negligible resistance to flow. For comparison the Hans Rudolph 2700 valve that is often used for exercise develops a

Figure 4 Maximum change in $F E V$, after exercise breathing cold air through dummy and active masks.

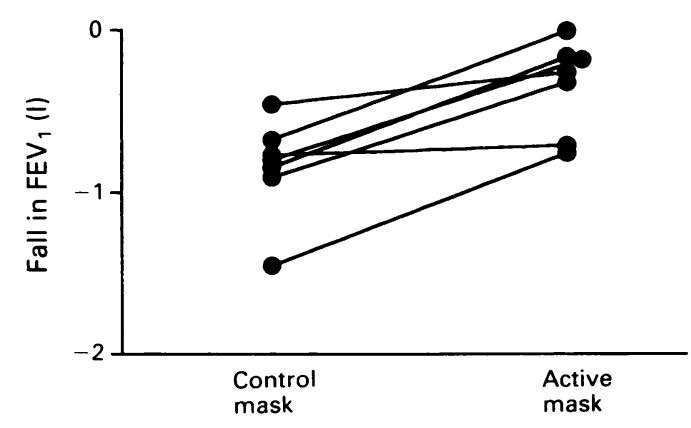

$3.8 \mathrm{~cm} \mathrm{H}_{2} \mathrm{O}$ pressure gradient at $5 \mathrm{l} / \mathrm{s}$ compared with $1 \mathrm{~cm} \mathrm{H}_{2} \mathrm{O}$ at $6 \mathrm{l} / \mathrm{s}$ for the heat and moisture exchange mask. Thus the mask can be worn comfortably for prolonged periods. The materials used in anaesthetic heat and moisture exchange devices allow for heat transfer at the low flow rates encountered in anaesthetic circuits but all have significant resistance even at these low rates, and this becomes intolerable during exercise. The multiple small channels in the hygroscopically treated foam or paper elements within some of these devices take up and hold significant quantities of water, resulting in further increases in resistance. ${ }^{8}$

The warming within the dead space of a mask may explain the positive findings in the study that used surgeons' paper masks. ${ }^{7}$ Our control mask, which had a similar dead space to the active mask, produced some warming of the inspired air and a trend towards less bronchoconstriction, but these changes were significantly less than those seen with the active heat and moisture exchange mask. Most of the heat stored in the heat and moisture exchange during exhalation is probably in the form of condensed moisture and the associated latent heat of condensation. To measure inspired moisture content directly is difficult and not possible in our circuit. If the expired air is assumed to be $100 \%$ saturated with moisture and the inspired air is only $75 \%$ saturated by the mask the percentage of exhaled water recovered by the following inhalation over and above that contained in the ambient air can be calculated to be $42 \%$ during breathing of air at $24^{\circ} \mathrm{C}$ and $43 \%$ during breathing of cold air at $-16^{\circ} \mathrm{C}$. The calculation is shown in the appendix. Thus, although the temperature rise when air is breathed at subzero temperatures is much more impressive than at room temperature, the percentage of water and thus latent heat of condensation recovered is similar. Similar calculations can be performed to show that if the inspired air is $100 \%$ saturated by the mask the efficiency of water recovery would be of the order of $65 \%$. Perhaps the most important feature of this new heat and moisture exchanger is its ability to maintain its efficiency at high flow rates such as are seen during maximum voluntary ventilation and exercise. The most likely explanation for this effect lies with the high latent heat of condensation. Thus the heat stored in association with a change from gas to fluid phase greatly exceeds that which can be stored as a result of a temperature change alone.

The severity of exercise induced bronchoconstriction is known to vary substantially between individuals despite similar degrees of resting pulmonary function. ${ }^{9}$ During the cold air challenge patients with the smallest falls in $\mathrm{FEV}_{1}$ after exercise derived least benefit from the heat and moisture exchange mask and also had less warming of the inspired air by the mask. In contrast, in experiment 1 the fall in $\mathrm{FEV}_{1}$ with exercise in one subject was uninfluenced by change in temperature; subsequent testing showed that his exercise induced asthma was not improved by prophylactic drug treatment. 
Increased levels of exercise cause a greater degree of bronchoconstriction. ${ }^{1011}$ Although we fixed our work rate, the breathing pattern adopted by subjects may have changed as cold air can stimulate ventilation by its effects on nasal receptors. ${ }^{12}$ Thus there may have been more respiratory heat loss with the active mask at a given workload than is suggested by calculations based on temperature and work rate alone.

After exercise a degree of bronchodilatation occurs before bronchoconstriction occurs. This was not seen in any patient with the control mask in the cold air study whereas four patients showed some bronchodilatation when using the active heat and moisture exchange mask. This suggests that bronchoconstriction develops during exercise and can be blocked by breathing warmed air. The maximum benefit from a heat and moisture exchange mask will probably be obtained if use is continued during the early recovery period.

In summary, we describe a new heat and moisture exchange mask that reduced the severity of exercise induced bronchoconstriction in the laboratory. It may be useful in the further investigation of the mechanisms of exercise induced asthma and may be of practical value for asthmatic patients in noncontact sports and for workers in cold storage units. This approach to regulating air temperature may prove useful in other patients in whom cold air can provoke symptoms.

1 Anderson SD. Current concepts in exercise induced asthma Allergy 1983;38:289-302.

2 Deal EC, McFadden ER, Ingram RH, Strauss RH, Jaeger JJ. Role of respiratory heat exchange in production of exercise induced asthma. J Appl Physiol 1979;46:467-75.

3 Anderson SD, Schoeffel RE. Sensitivity to heat and moisture loss at rest and during exercise in patients with asthma. loss at rest and during exercise in

4 Sheppard D. What does exercise have to do with "exercis induced asthma"? Am Rev Respir Dis 1987;136:547-9.

5 Chen WY, Horton DJ. Heat and water loss from the airways in exercise induced asthma. Respiration 1977;34:305-13.

6 Chen WY, Weiser PC Chai H. Airway cooling, stimulus for exercise induced asthma. Scand J Respir Dis 1979;60: 144-50.

7 Brenner AM, Veiser PC, Krogh LA, Loren ML. Effectiveness of a portable mask in attenuating EIA. JAMA 1980;244:2196-8.

8 Department of Health and Social Security. Health equipment bulletin (March). London: DHSS, 1988.

9 Karjalainen J. Exercise response in 404 young men with asthma: no evidence for a late asthmatic reaction. Thorax 1991;46:100-4.

10 Silverman $M$, Anderson SD. Standardisation of exercise tests in asthmatic children. Arch Dis Child 1972;47:882-9.

11 Nosiski N, Bar-Yishay E, Gur I, Godfrey S. Exercise intensity determines and climatic conditions modify the severity of exercise induced asthma. Am Rev Respir Dis 1987;136:592-4.

12 Burgess KR, Whitelaw WA. Effects of nasal receptors on pattern of breathing. J Appl Physiol 1988;64:371-6.

\section{Appendix}

Water content of expired air (mean temp $35^{\circ} \mathrm{C}$ )

$42 \cdot 2 \mathrm{~mm} \mathrm{Hg}$

Water content of ambient air $\left(24^{\circ} \mathrm{C} 50 \%\right.$ relative humidity)

$11.7 \mathrm{~mm} \mathrm{Hg}$

Water content of inspired air $\left(30 \cdot 5^{\circ} \mathrm{C}, 75 \%\right.$ relative humidity)

$24.6 \mathrm{~mm} \mathrm{Hg}$

$\%$ Water recovery $=\frac{24 \cdot 6-11 \cdot 7}{42 \cdot 2-11 \cdot 7}=\frac{12 \cdot 9}{30 \cdot 5}=42 \%$

COLD AIR

Water content of exhaled air $\left(34^{\circ} \mathrm{C}\right)$

Water content of cold air $\left(-16^{\circ} \mathrm{C}\right)$

$39.9 \mathrm{~mm} \mathrm{Hg}$

$1.0 \mathrm{~mm} \mathrm{Hg}$

Water content of inspired air $\left(24^{\circ} \mathrm{C}, 75 \%\right.$ relative humidity)

$17.8 \mathrm{~mm} \mathrm{Hg}$

$\%$ Water recovery $=\frac{17 \cdot 8-1 \cdot 0}{39 \cdot 9-1 \cdot 0}=\frac{16 \cdot 8}{38 \cdot 9}=43 \%$ 